International Journal of Engineering \& Technology, $7(4.3)(2018) 414-418$
International Journal of Engineering \& Technology
SPC
Website: www.sciencepubco.com/index.php/IJET
Research paper

\title{
Fulfillment in Logistic Infrastructure of International Internet-Trade of Ukrainian Companies
}

\author{
Vitalii Diachek $^{1}{ }^{*}$, Olga Diachek $^{1}$, Tetiana Shuba ${ }^{1}$ \\ ${ }^{1}$ V.N. Karazin Kharkiv National University \\ *Corresponding author E-mail: diachekv@gmail.com
}

\begin{abstract}
The article describes the concept of fulfillment, its essence and role for ensuring effective international trade on the Internet. The structure and complex of basic and additional services of fulfillment were considered. The authors gave the specific features of fulfillment that define this type of activity. The advantages and disadvantages of fulfillment outsourcing were determined. It was justified the expediency of transferring this activity to a fulfillment operator, especially in cases when small companies and start-ups start to trade internationally. The structure and algorithm of providing fulfillment services by the operators were analyzed.
\end{abstract}

Keywords: E-commerce; fulfillment; international trade; logistics; outsourcing; start-up.

\section{Introduction}

Today, more and more customers prefer online shopping instead of traditional merchandise, with consumers becoming increasingly demanding in terms of delivery method and delivery time, type of payment, and service level. Despite the crisis, the Internet commerce market in Ukraine is growing rapidly, and products are increasingly being posted on the Internet. Thus, the report of the European E-Commerce Association Ecommerce Europe says that the e-commerce market in Ukraine is growing faster than any other in Europe, the growth rate of online sales in Ukraine remains at $35 \%$. This is contributing to the fact that in the e-commerce market there are more and more new members who face the problem of performing all business processes on their own or transfer these tasks to outsourcing. These problems arouse rapidly when companies start to do business internationally. Therefore, in the near future, most players in the e-commerce market are expected to consciously switch to outsourcing, which will lead to an increase in demand for special logistics services for individual distance trading - fulfillment.

\section{Analysis of Recent Research and Publications}

Analysis of the development of such phenomenon as fulfillment has recently been given a lot of attention. The issues were considered by the following researchers: O. Zhukov, V. Klimov, V. Baranovsky, V. Leonov, A. Upatov, who analyzed the participants of the fulfillment market, and also covered practical experience in the field of fulfillment. However, in our opinion, the disclosure of the characteristics of fulfillment as a direct line of activity of the logistics company or as an outsourcing service is not enough. The purpose of the article is to identify the nature, characterization and research of the technology of the fulfillment process as a new business service in the e-commerce market; determine the advantages and disadvantages of outsourcing fulfillment; substantiate the expediency of transferring this area of activity to the ful- fillment operator, as well as analyze the current state of the fulfillment market in Ukraine.

\section{Main Part}

Online shopping, as one of the outsourcers, holds a significant share in the retail trade and the popularity of selling goods over the Internet shops, which has been steadily increasing in recent times due to savings in retail spaces and contemporary international express delivery make the procedure for getting goods easier for buyer.

The world's online companies have long focused on the development of logistics, giving impetus to the emergence of a new service - fulfillment. Fulfillment is a complex of logistic operations from the moment the order is completed by the buyer and before the purchase. Delivering its effectiveness, the service began to gain popularity not only in the US market, but also in all countries with the rapid development of the e-commerce segment.

Beginner in business and those who have already come to profit are not yet ready to set up their own logistics. It often turns out to be ineffective because of seasonal sales fluctuations and unforeseen depreciation costs, while fulfillment prevents these risks. Therefore, entrepreneurs choose another way: they sell, work with assortment, negotiate with manufacturers and suppliers, and deliver the warehouse and delivery to qualified contractors [3].

Fulfillment for online stores is a comprehensive system approach to outsourcing logistics that provides the full range of warehouse and transport processing customer orders. Fulfillment services, depending on the wishes of the seller, may include full or partial unloading of the functional for the warehouse accounting of goods, the formation of orders and sending them to the place of receipt. The transition to fulfillment in Ukraine, the price of which is becoming more profitable for logistics, is an objective consequence of the growth of sales in online stores [2].

The first step to fulfillment service usage is to find a contractor using catalogues and ratings only through specialized industrial 
sources. Next, it should be considered what criteria should be applied in the fulfillment of operator selection.

First of all, you have to find out the cost of services specifically for company products, as fulfillment is a set of transactions with the goods, and certain transactions are resources costs. Every business is unique, so the cost should be calculated separately, given the characteristics of the goods, their weight and size. It is necessary to pay attention to the operator tariffs and their components. For example, it can be a fee for each transaction (one order processing, packing per order and so on), or a percentage of the turnover of the client (the higher the turnover, the lower the percentage). However, there are various additional conditions (for example, a separate service charge is not included in discussion volume). Also, you should note the presence of user fees. This is advantageous because the company sells to pay the monthly fee even with no transactions in the accounting period, but for the company this means unnecessary costs. The availability of package deals is also interesting. In this case, fulfillment operator of fers a fixed price for a certain number of items. But if the number of items is less, fixed costs still have to be paid. The usage of this approach is only valid if the company is confident in the number of future items.

Attention should be paid to the geographical position of the operator. For example, if the company is located in the south of Ukraine and fulfillment operator is in the north, the whole process of transporting goods from the company to the warehouse operator will take much time and incur significant costs. It is necessary to compare all expenditure (gasoline, travel time and downtime in a traffic jam) with the potential benefits of fulfillment services. It is likely that small savings using fulfillment will result in a tenfold cost of transportation.

Thirdly, you need to know about discounts on shipping. Often fulfillment centers provide discount rates of service delivery. The higher the volume of shipments operator delivers, the greater the discount is. Sometimes the operator is willing to share part of discounts to attract customers. Special attention should be paid to the study and the conclusion of a contract where cooperation must me stated, the best option is to cooperate on a "departure is a payment; No items - no pay ". That is the contract company fulfillment operator is not obliged to provide download service orders and can use their services when necessary.

In order to choose the operator you should elaborate the main needs and peculiarities of business organization to your partner. The more information about the shops will be given, the more accurate the contractor will pick up services that meet exactly these needs.

The complete logistics cycle of fulfillment services can be divided into several main stages:

1. Receiving the goods from the supplier. Not having their own warehouse space, online shops often conduct business on the principle of dropshipping, purchasing goods from the supplier after the receipt of an application from the end user for its purchase. Therefore, when organizing the delivery of goods to a warehouse, for example, «Zammler» takes over the entire process of interaction with the supplier, offering two options: the product is stored on the fulfillment warehouse, and after the receipt of the application online, the company's staff process orders and send courier services for delivery to the end customer; consolidated fence of goods from the supplier immediately for several online stores and its delivery to the warehouse (Figure 1) [4].

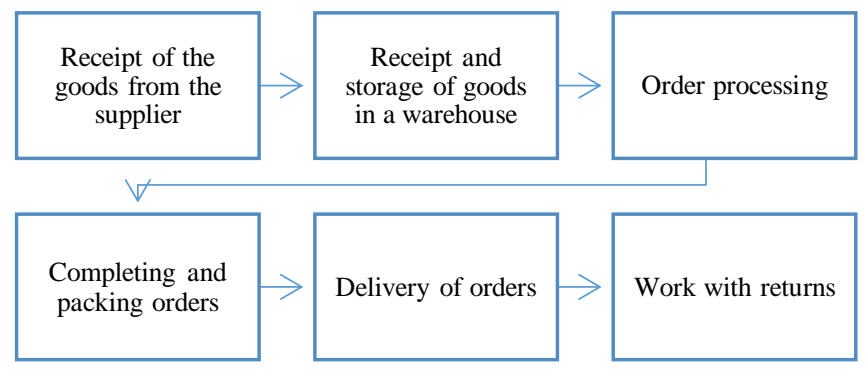

Fig. 1: The components of fulfillment services.

2. Reception and storage in stock. After delivery to the warehouse, the goods are registered in the warehouse system and sent to storage. The WMS system used in «Zammler» allows you to take into account all the specific characteristics of the product, different format and dimension of the parties. Thanks to the WMS system, the product is optimally placed on shelves. If the received goods must be sent to the buyer on the same day, it is immediately sent to the processing area of orders.

3. Processing orders. For communicating with an online store, the company developed the CRM-system, which consolidates information about the status of customer orders. You can track everything: from the moment of sending the goods to the warehouse until the moment it is delivered to the consumer or return to the warehouse. The period from the receipt of the order from the client to the transfer of the order for delivery takes 2 hours. Each client receives access to his "personal office" and can monitor online inventory and the state of processing and delivery of orders. 4. Package and packing order. Skilled warehouse staff perform packaging, marking, parceling, as well as - completion of accompanying documentation. Customers can also order brand packaging or supplement orders when completing any printed product.

5. Delivery. After completing the goods, they are delivered to the delivery department or carrier company. For example, «Zammler» can collaborate with various logistics contractors (postal, courier companies), which allows the online store to offer buyers various delivery options, cover the maximum geography of delivery at the best prices. For communication with the end user, Zammler fulfillment operates a call-center. Its function is to process calls to coordinate delivery times or to resolve situations when the ordered position has not yet arrived from the supplier.

6 . Work with returns. If the buyer has decided to return the goods, then the return is taken by the staff of the composition with the photo fixation (in agreement with the client) and additional quality check. After that, the goods are sent for further storage or returned to the supplier [4].

There are three key consumer groups of fulfillment services:

1. Online stores. At the start of the online store there are no builtin processes. It needs a partner who will provide all kinds of services at a minimal cost.

2. Suppliers and retailers who want to go online. Retail and suppliers already have their warehouses, logistics, IT systems. Basically, they need a set of services associated with storing and drawing up some orders.

3. Foreign companies without presence in Ukraine [5].

By developing a new direction for the market as a fulfillment for online stores, Ukraine is getting a fairly effective tool for maximizing profits and flexible spending management. UVK-Ukraine, a professional logistics operator and full-fledged center, offers its customers the following orders management services (Figure 2).

1. Online stores. At the start of the online store there are no builtin processes. It needs a partner who will provide all kinds of services at a minimal cost.

2. Suppliers and retailers who want to go online. Retail and suppliers already have their warehouses, logistics, IT systems. Basically, they need a set of services associated with storing and drawing up some orders. 


$\begin{gathered}\text { Full or partial integration with client systems for accounting and order } \\ \text { management, their reception and processing }\end{gathered}$
Processing and storing of any goods, providing the equipped
warehouse of the fulfillment center
$\begin{gathered}\text { The full fulfillment logistics - acceptance of goods, their repackaging } \\ \text { and the formation of metro units, complete set of orders of any } \\ \text { complexity and other operations }\end{gathered}$
Marking and packaging of goods using standard or branded
packaging
Work with returned orders
Delivery to any city that covers fulfillment for online stores with
complete document circulation and insurance
The possibility of consignment trade, organized through the customs
warehouse

Fig. 2: Types of order management services.

\section{Foreign companies without presence in Ukraine [5].}

By developing a new direction for the market as a fulfillment for online stores, Ukraine is getting a fairly effective tool for maximizing profits and flexible spending management. UVK-Ukraine, a professional logistics operator and full-fledged center, offers its customers the following orders management services:

1.Full or partial integration with client systems for accounting and order management, their reception and processing

2.Processing and storing of any goods, providing the equipped warehouse of the fulfillment center

3.The full fulfillment logistics - acceptance of goods, their repackaging and the formation of metro units, complete set of orders of any complexity and other operations

4.Marking and packaging of goods using standard or branded packaging

5. Work with returned orders

6.Delivery to any city that covers fulfillment for online stores with complete document circulation and insurance

7.The possibility of consignment trade, organized through the customs warehouse

Also, to ensure the reliability of the company, one needs to know how many years of operating experience the company has. Young players are more actively competing for customers and can give bonuses to new customers.

On the other hand, the longer the company exists in the market, the broader its practical experience is and the more problems for the operator have moved into the category of trivial, but their solutions are studied. It is necessary to clarify fulfillment operator if he worked with a company like a company-seller.

The main fulfillment advantages and disadvantages are aggregated in the table 1.

Table 1:Advantages and disadvantages of outsourcing logistics functions to fulfillment operators

\begin{tabular}{|c|c|c|}
\hline № & Advantages & Disadvantages \\
\hline 1 & Cost optimization & \multirow{2}{*}{$\begin{array}{c}\text { Reliance on fulfillment } \\
\text { operator }\end{array}$} \\
\hline 2 & $\begin{array}{c}\text { Reducing the capital costs for } \\
\text { warehouses, etc. }\end{array}$ & \\
\hline 3 & Reducing personnel costs & Information risks \\
\hline 4 & Reducing IT costs & $\begin{array}{c}\text { Availability of additions in } \\
\text { the supply chain, which } \\
\text { impairs the processing of } \\
\text { claims }\end{array}$ \\
\hline 5 & Risk diversification & $\begin{array}{c}\text { Improving the quality and speed } \\
\text { of delivery of the finished items }\end{array}$ \\
\hline
\end{tabular}

So, as we see there advantages and disadvantages of outsourcing logistics functions to fulfillment operator, which forms the requirements to the operator.

According to statistics, the number of online stores in Ukraine has doubled in the course of one year [5,6]. The rapid dynamics of the online trading market and the growth of demand for address services continue to be reflected in the company's performance [6, $10]$.
In Ukraine, the fulfillment market is only forming, it is very young, and there are only five or six players [5]. Fulfillment deals with "Nova Poshta". This direction is engaged in "NP Logistik" company which is part of "Nova Poshta" group, the only representative in the Ukrainian market, a player working under the formula "fulfillment + delivery". Today it is the only company in the Ukrainian market that provides services for receiving, storing, packing, packaging and delivering goods to the end user (Figure $3)$.

The company sends the goods to the warehouse "NP Logistik"

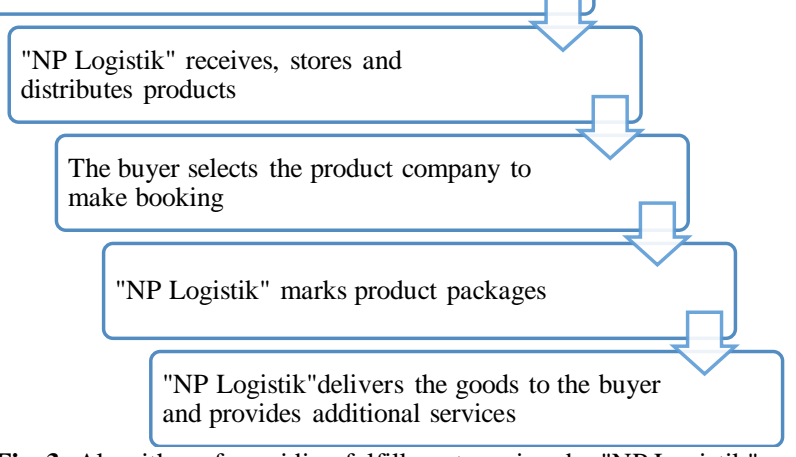

Fig. 3: Algorithm of providing fulfillment services by "NP Logistik".

This trend is due to the fact that online stores that make more than 100 shipments a day are very profitable to shift logistics to outsourcing: business owners have the opportunity to devote more time to business development than to thinking about delivery. Also, fulfillment helps cope with seasonal sales spikes [6].

To have one's own warehouse logistics in most major online stores is extremely inefficient: it is difficult and costly to build logistics itself. There are two main cost items. First, investments in the warehouse: the arrangement of workplaces and the environment for employees, warehouse equipment, trucks, rent space. Renting a good class A is worth hundreds of thousands of USD a year. Given the seasonality of business, it should accommodate all goods in peak periods. However, the area will be empty in the periods of decline but all the same it will have to be paid for, which will affect the cost of shipping.

The second item of expenditure is IT. Without good software and automation of the warehouse system, it is impossible to provide logistics on a large scale. Installing good software takes a lot of time and it is very costly. The total cost of space, technology, equipment and people is measured in millions [7,9].

Outsourcing companies like "NP Logistik" gives online stores a finished product, minimizing risks. At the same time, their operating costs are immediately reduced by $30-40 \%$, and processes are significantly accelerated. In December 2015, the number of orders that "NP Logistik" handled and delivered to the Rosetka, was 6000 per day, and by January 2017 this figure exceeded 15,000 per day.

However, the main disadvantage of fulfillment should be called the loss of control. By giving all the logistics processes to the outsourcing, the retailer falls into dependence on this company. In order not to be in such a situation, for example, Rosetka partially carries out logistics on its own, and partially turns to outsourcing, and thus the dependence on the operator is offset [9].

Today in the regions there are no specialized warehouses and companies that are ready to serve Internet trade outside Kyiv. Ukrainian fulfillment market is still very young, therefore, first of all, efforts should be made to develop the infrastructure, to establish technical processes, to structure the market. Thus "NP Logistik" plans to develop branches in the cities-millionaires.

One of the ways to increase the efficiency of activities and the international competitiveness of companies in the sphere of fulfillment is the introduction of social responsibility principles into their activities. Using such principles and technologies will allow the company to achieve such advantages as: increasing loyalty to the company from customers, the state and local communities, strengthening relationships with intermediaries and suppliers, 
gaining additional profits in the long term, and strengthening the company's position both on domestic and in the foreign market.

In the Ukrainian market, unfortunately, the companies in the sphere of fulfillment are not sufficiently informed not only about the benefits of introducing the principles of social responsibility, but also about the mechanisms for introducing and implementing such.

A successful example of the Ukrainian company providing services in the sphere of fulfillment, which operates on the principles of socially responsible business is the group of companies Zammler. Zammler Group includes 6 companies represented in 8 countries of the world (Figure 4).

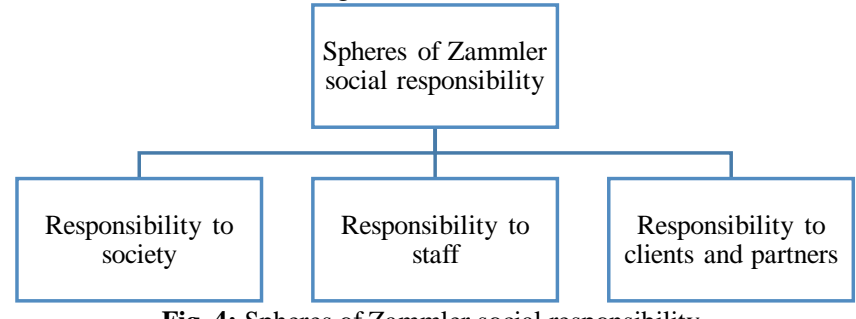

Fig. 4: Spheres of Zammler social responsibility.

The spheres of social responsibility in which the main activity of Zammler carries out are presented in Figure 4. Thus, it can be said that the company's social responsibility is directed to both the external and internal environment.

Zammler supports and initiates targeted charitable projects aimed at [12]:

1. assistance to orphans and children deprived of parental care;

2. equipping hospitals with the necessary equipment;

3. assistance in the treatment of seriously ill children;

4. support for the military in the area of the ATO.

We can say that the fundamental principle of social responsibility in the sphere of fulfillment is the principle of transparent business conduct. Providing a clear and understandable mechanism for the implementation of business makes it possible to provide trust from customers and client companies. In addition, the prescribed rules of conduct in a given situation greatly simplifies the functioning of the enterprise by the staff. Based on the above, it is possible to propose the following steps to implement the principle of transparent business (in the sphere of fulfillment):anti-corruption measures; promotion of corporate transparency (including, disclosure of information about owners); transparency in the disclosure of information; development of a corporate code of conduct; interaction only with counterparties, which also support the principles of socially responsible business.

However, the biggest problem for the development of fulfillment in Ukraine is the lack of awareness of entrepreneurs: potential customers have to explain what it is and why it is needed. Many entrepreneurs have only heard about such a service, but most do not imagine how it can ease life and give a boost to business development [9].

In addition to the rapid growth of the e-commerce segment, cost optimization will continue to be a driver of the fulfillment market, especially for small companies and start-ups. Previously, companies took a decision in favor of controlling their logistics, but nowadays a priority for big players is to view costs. Yes, those companies that recently worked on their logistics now outsource storing, processing and mailing PSM-materials. This will enable Ukrainian players to develop good experience and the basis for its development in the fulfillment market [3].

After passing the whole process of product work on outsourcing, the client can focus on their internal business processes and not worry about delivering the product exactly at the address and in the required timeframe [11].

Thus, when fulfillment is well-organized, the Internet store gets reduced operating costs and lack of significant investment; flexibility in the logistics service, which is expressed in the scalability of logistics services; concentration on key processes for business development $[4,8]$.
In the coming years, the fulfillment market will evolve at the expense of two factors - the positive dynamics of e-commerce and the diversification of sales channels. In Ukraine, outsourcing logistics is important to be made convenient not only for large customers who store goods with hundreds of pallets, but also for small ones, the number of which is becoming higher and higher [11].

\section{Conclusions}

After analyzing the research material, it can be noted that perfection of the fulfillment business will be a decisive step for the growth of the e-commerce market, and therefore the relationship of fulfillment operators with online stores is a promising direction for the development of their activities.

World practice shows that the formation of a partnership between the fulfillment operator and its client is beneficial to both parties, and their presence serves as a driver for the growth of the entire ecommerce market.

It should be borne in mind that small companies can face with different internal problems of their growth and external problems of unstable domestic economy, so fulfillment can be the mean of penetration international market. It allows companies to reduce the costs of warehouses, communications, staff, customs clearance for export and import, as well as getting payment from customers. Also it helps to penetrate international market and transfer the way of doing business internationally, forms of corporate social responsibility from fulfillment operator to small companies and start-ups. In addition fulfillment operator provides not only logistics services but some kind of consultation in business.

Although the fulfillment is different from traditional logistics, it is effective due to the existing advanced logistics infrastructure, modern information technology and high level of organization of technological processes. Fulfillment market of developing countries like Ukrainian is in creating phase that is why there are prospects for its expansion, which can require further research. and avoid placing them in the middle of columns. Any table or figure that takes up more than 1 column width must be positioned either at the top or at the bottom of the page

Photos must be crystal clear with such resolution to allow fine details visibility. The elements from any photo must be explained using numbers, letters, etc. The text within a figure or photo must have the same style, shape and height as the caption has.

Any table, figure or picture must have a caption (Fig. 1, Table 1, etc.) followed by a proper description. All similar graphics must be generated using the same software product (Excel, Origin, Mathematica, etc.). Importing graphics into the article as images (JPG, BMP, PNG, etc.) should be avoided. All similar electronic schematics, charts, program flow, simulated characteristics, etc. from the article should be generated using the same software product. Importing images from other articles or books it's totally forbidden unless they are cited.

\section{References}

[1] Fulfillment, what is it?, available online: http://partnertrade.org/fulfilment-chto-eto-takoe/

[2] Fulfillment services for online stores, available online: https://www.uvk.ua/en/uslugi/fulfilment-i-dopolnitelnyelogisticheskie-uslugi/

[3] As the warehouse deficit affects the development of small businesses, available online: http://ukraine.web2ua.com/kak-deficitskladov-vlijaet-na-razvitie-malogo-biznesa-3093/

[4] Fulfillment-logistics and maintenance of online stores, available online:

https://www.zammler.com.ua/en/services/warehousing/fulfilment/

[5] Fulfillment - what is it and how it is used, available online: http://jak.magey.com.ua/articles/fulfilment-fulfillment-shho-cetake-i-jak.html

[6] How the fulfillment of the company "Nova Poshta" works, available online: https://ain.ua/2017/02/09/kak-rabotaet-fulfilment-novojposhty-fotoreportazh-iz-centra-v- brovarax 
[7] Global trend - fulfillment - gaining momentum in Ukraine, available online: http://logist.fm/publications/mirovoy-trend-fulfilmentnabiraet-oboroty-v-ukraine

[8] "NP Logistik": demand for fulfillment is growing rapidly, available online: https://novaposhta.ua/news/rubric/2/id/4203

[9] Services - Fulfillment, available online: http://www.logisticplus.com.ua/index.php?cat=209\&lang=eng

[10] Composition on outsourcing: how Nova Poshta works, available online: https://rau.ua/experience/fulfillment-nova-poshta/

[11] Fulfillment, available online: http://fulfilment.novaposhta.ua/\#additional_services
Social responsibility, available online: [12] Social responsibility,
https://www.zammler.com.ua/ru/services/warehousing/fulfilment/ 